\title{
Literatura científica brasileira sobre ciência da informação em saúde indexada na Base de Dados LILACS de 1982-2006
}

Augustus Fanani

\author{
Graduado em Biblioteconomia e \\ Documentação pela UEL em 2006. \\ Aprimorando em Documentação e \\ Informação em Ciências da Saúde. \\ Bibliotecário da UNIRP.
}

Cláudia Araújo Martins

\author{
Graduada em Biblioteconomia e \\ Documentação pela UNESP/MARÍLIA em \\ 1995. Mestranda em Ciências da Saúde \\ pela FAMERP.Bibliotecária-chefe da \\ FAMERP.
}

O artigo apresenta uma análise estatística dos documentos relacionados à Ciência da Informação indexados na base de dados LILACS, como forma de identificar a produção dos profissionais da informação que atuam em Saúde. Os critérios considerados para caracterizar a produção foram: autor, assunto, local, ano e tipo de publicação. Os autores concluíram que a produção em Ciência da Informação em Saúde indexada é pouco expressiva se comparada ao conteúdo total da base.

Palavras-chave: Literatura Científica; Bibliometria; Indicadores Científicos; Ciência da Informação; Ciência da Saúde.

\section{Brazilian Scientific Literature about Health Information Science indexed on LILACS Database from 1982 to 2006}

This paper presents a statistical analysis of the documents related to the Information Science indexed on LILACS Database in order to identify the articles and publications 
of the information professionals working in Health Care. We have considered the following criteria to characterize the articles and publications: author, theme, local, year, and type of publication. The authors have concluded that the indexed publications on Health Information Science are not significant when compared to the whole content of the database.

Keywords: Scientific Literature; Bibliometrics; Scientific Indicators; Information Science; Health Science.

Recebido em 01.01.2008 Aceito em 13.10.2008

\section{Introdução}

A Ciência da Informação não possui, ainda, uma teoria capaz de englobar todos os seus conceitos e práticas (SARACEVIC, 1996; OLIVEIRA, 2005). Estudiosos da área utilizam uma conceituação ora mais ampla, ora mais restrita, para identificar o que é informação, seu universo de atuação, e para estabelecer os domínios e particularidades do profissional da informação (ARRUDA; MARTELETO; SOUZA, 2000; OLIVEIRA, 2005; CAPURRO; HJORLAND, 2007).

Apesar de ser uma ciência ainda em construção, sua principal característica é a de investigar e apurar os domínios e o comportamento da informação, ou seja, sua criação, seu fluxo e seu desempenho final, que seria a aplicação ou não dessa informação pelo usuário (BRAGA, 1995).

Segundo alguns autores, a Ciência da Informação possui várias ramificações e especialidades, tais como a Biblioteconomia, a Ciência da Computação, a Comunicação Social, a Administração, a Lingüística, a Psicologia, a Lógica, dentre outras (TARAPANOFF; SUAIDEN; OLIVEIRA, 2002; OLIVEIRA, 2005).

Em se tratando da Biblioteconomia, foco desse trabalho, podemos identificar outras ramificações e áreas distintas de atuação, como, por exemplo, a Agricultura, a Saúde, a Indústria, o Direito, e tantas outras, em crescente movimento devido à sua evolução e à ampliação do mercado de trabalho (BARBOSA, 1998; MIRANDA; SOLINO, 2006).

A aplicação da Biblioteconomia em Ciências da Saúde vem ganhando espaço à medida que os avanços tecnológicos influenciam a criação, a ordenação, a coleta, a armazenagem, a recuperação, a disseminação, e a utilização da informação científica em saúde.

Um levantamento realizado por Rogério Meneghini e Abel Packer (2006), com o objetivo de identificar grupos de excelência, demonstra que as ciências da vida, como é chamada a junção das áreas da saúde e 
biológicas, correspondem a dois terços dos artigos brasileiros mais citados.

Em uma década, as áreas de medicina e cirurgia geraram 68 artigos em periódicos internacionais que obtiveram mais de 100 citações. A pesquisa biomédica, outros 67. E a biologia, 29. As três juntas perfazem $66 \%$ do total de 248 artigos com esse alto nível de impacto (LEITE, 2005, p. 1).

Este estudo ilustra a proporção da produção em saúde perante a das demais áreas da ciência e evidencia o volume de informações geradas por e utilizadas pelas Ciências da Saúde.

Conseqüentemente, inferimos que o trabalho bibliotecário tem se tornado imprescindível, no que diz respeito ao tratamento e à disponibilização da informação aos usuários especializados, uma vez que tudo o que se refere à informação e à sua recuperação está direta ou indiretamente ligado ao profissional da informação, sendo que este deve ter alguns atributos e iniciativas que beneficiem seu público (MARTINS; KAVANAMI; FANANI, 2007).

Segundo Pereira (2005), os profissionais ligados à área da saúde convivem com um duplo trabalho em mãos. O primeiro com relação à especialidade, pois, uma vez trabalhando em uma área específica, o profissional deve se adaptar ao que é próprio da área; e o segundo com relação ao volume de informações, pois em bibliotecas da área médica elas ocorrem a todo o momento, fazendo com que o profissional da informação tenha de ser mais dinâmico para trazê-las em tempo real ao seu usuário.

\section{Justificativa}

Com o objetivo de checarmos a produção científica do bibliotecário e sua apropriação das Ciências da Saúde com o viés da Ciência da Informação, realizamos esse estudo bibliométrico, que visa identificar e conhecer a produção científica brasileira indexada na base de dados LILACS (Literatura Latino-Americana e do Caribe em Ciências da Saúde), de 1982 até 2006.

\section{A base de dados LILACS}

A base de dados LILACS (Literatura Latino-Americana em Ciências da Saúde) reúne a literatura científica relativa às Ciências da Saúde publicada nos países latinos. Foi criada em 1982, pela BIREME (Centro Latino-Americano e do Caribe de Informações em Ciências da Saúde) em parceria com a OPAS (Organização Panamericana de Saúde) e a OMS (Organização Mundial de Saúde).

Atualmente possui 751 títulos de periódicos correntemente indexados, além de teses, livros, capítulos de livros, anais de congressos, 
relatórios técnico-científicos e publicações governamentais. É destinada aos pesquisadores e profissionais da área da saúde.

A LILACS é um dos produtos oferecidos pela BVS (Biblioteca Virtual em Saúde), por meio do endereço eletrônico http://www.bvs.br1, e está "em contínuo desenvolvimento, constituído de normas, manuais, guias e aplicativos, destinados à coleta, seleção, descrição, indexação de documentos e geração de bases de dados" (CENTRO..., 2006, p. 1).

\section{Metodologia}

Inicialmente realizamos uma busca bibliográfica ampla sobre todos os trabalhos indexados que tinham alguma relação com a Ciência da Informação, utilizando a técnica de "explodir" a categoria. O procedimento foi feito da seguinte forma: na base de dados LILACS escolhemos o formulário avançado, selecionamos o índice "descritor de assunto", e no campo correspondente escrevemos a expressão "EX L01\$". Esta operação resultou em 13.210 trabalhos.

Em uma primeira inspeção, notamos que os resultados mostravam assuntos diversos e que a grande maioria não tinha necessariamente relação com a Biblioteconomia. Dessa forma, fizemos uma extração de 62 descritores de assuntos ${ }^{2}$ que consideramos mais pertinentes, por meio da verificação da categoria hierárquica: Ciência da Informação (L01).

O levantamento bibliográfico realizado utilizando esses descritores e o idioma português retornou como resultado1669 documentos.

A quantidade de trabalhos recuperados utilizando cada um dos descritores é demonstrada na TAB. 1.

\footnotetext{
Acesso em: 17 nov. 2008.

${ }^{2}$ Vocabulário controlado utilizado para indexação de assuntos em Ciências da Saúde.
} 
TABELA 1 - Descritores utilizados para realizar o levantamento bibliográfico

\begin{tabular}{|c|c|c|c|}
\hline DESCRITOR & QUANT & DESCRITOR & QUANT \\
\hline Acervo de Biblioteca & 02 & Classificação de Livro & 01 \\
\hline Acesso à Informação & 16 & Colecionamento de Livros & -- \\
\hline Administração de Biblioteca & 02 & Descritores & 23 \\
\hline $\begin{array}{l}\text { Armazenamento e Recuperação da } \\
\text { Informação }\end{array}$ & 26 & $\begin{array}{llll}\begin{array}{l}\text { Desenvolvimento } \\
\text { Bibliotecas }\end{array} & \text { de } & \text { Coleções } & \text { em } \\
\end{array}$ & 02 \\
\hline Arquivamento & 01 & Direitos Autorais & 03 \\
\hline Arquivos & 25 & Disseminação de Informação & 12 \\
\hline Associações de Biblioteca & -- & Disseminação Seletiva da Informação & -- \\
\hline Automação de Bibliotecas & 01 & Documentação & 64 \\
\hline Bases de dados bibliográficas & 72 & Editoração & 76 \\
\hline Bases de dados de citações & 01 & Empréstimos entre Bibliotecas & 01 \\
\hline Bases de dados de texto completo & -- & Escolas de Biblioteconomia & -- \\
\hline Bases de dados estatísticos & -- & Gerenciamento de Informação & 21 \\
\hline Bibliografia de Medicina & 14 & Indicadores Bibliométricos & -- \\
\hline Bibliografia Descritiva & 01 & Levantamentos de Bibliotecas & 01 \\
\hline Bibliografia Nacional & 01 & MEDLINE & 19 \\
\hline Bibliometria & 45 & Portais de acesso a revistas científicas & -- \\
\hline Bibliotecários & 04 & Publicações & 52 \\
\hline Bibliotecas & 08 & Publicações Científicas e Técnicas & 05 \\
\hline Bibliotecas de Enfermagem & 03 & Publicações de Divulgação Científica & -- \\
\hline Bibliotecas Digitais & 02 & Publicações Periódicas & 344 \\
\hline Bibliotecas Hospitalares & 04 & PubMed & 01 \\
\hline Bibliotecas Médicas & 28 & Resumos e Indexação & 40 \\
\hline Bibliotecas Odontológicas & 04 & Seleção de Livros & 02 \\
\hline Bibliotecas Virtuais & -- & Serviços de Atendimento & 08 \\
\hline Biblioteconomia & 04 & Serviços de Biblioteca & 02 \\
\hline Biblioterapia & 05 & Serviços de Informação & 102 \\
\hline Catalogação & 02 & Serviços Técnicos de Biblioteca & 03 \\
\hline Catálogos de Bibliotecas & 06 & Sistemas de Alerta & -- \\
\hline $\begin{array}{l}\text { Centro Latino-Americano e do Caribe de } \\
\text { Informação em Ciências da Saúde }\end{array}$ & 02 & Sistemas de Avaliação das Publicações & -- \\
\hline Centros de Informação & 20 & Sistemas de Informação & 549 \\
\hline Ciência da Informação & 30 & Teoria da Informação & 08 \\
\hline
\end{tabular}

Fonte: Dados da pesquisa.

Após análise dos artigos, percebemos que apenas 249 (14.9\%) destes 1669 trabalhos se constituíam em documentos relevantes para a realização deste estudo sobre a Biblioteconomia em Saúde, uma vez que os demais, embora possuíssem descritores relacionados ao assunto, não abordavam a área em questão.

Excluindo os trabalhos duplicados, dos 249 foram selecionados apenas $93(37.3 \%)$, ou $0.7 \%$ do total de documentos relacionados à grande área Ciência da Informação, recuperados em nossa busca inicial usando a técnica de "explodir".

Esses 93 registros foram tratados estatisticamente para realizarmos uma análise bibliométrica do material indexado na base de dados LILACS, com o intuito de conhecermos os principais assuntos, data de publicação, tipo de material, local de publicação, número e gênero dos autores, a presença ou não de resumo; para assim traçarmos um panorama destas publicações. 


\section{Assuntos}

Os 93 documentos recuperados possuem 144 descritores diferentes. Destes descritores, $42(29,2 \%)$ são oriundos da categoria Ciência da Informação, os outros $102(70,8 \%)$ estão relacionados às outras categorias.

Se contabilizarmos o número de vezes que estes descritores se repetem, teremos uma lista com 340 assuntos, sendo que, destes, exatamente $50 \%$ correspondem à Ciência da Informação e o restante às outras áreas.

Assim, apesar de estarem em menor número, os descritores em Ciência da Informação apresentam três vezes mais documentos que as outras categorias.

A TAB. 2 apresenta os vinte assuntos mais mencionados e a quantidade de documentos relacionados a eles.

TABELA 2 - Descritores de assuntos dos artigos selecionados

\begin{tabular}{l|c}
\hline DESCRITOR & QUANT. \\
\hline \hline Bibliotecas Médicas & 20 \\
\hline Brasil & 16 \\
\hline Ciência da Informação & 13 \\
\hline Bibliografia Nacional & 12 \\
\hline Armazenamento e Recuperação da Informação & 11 \\
\hline Serviços de Informação & 11 \\
\hline Sistemas de Informação & 11 \\
\hline Internet & 10 \\
\hline Pesquisa & 08 \\
\hline Bases de Dados Bibliográficas & 06 \\
\hline Publicações Periódicas & 06 \\
\hline Bibliometria & 05 \\
\hline Bibliotecas Hospitalares & 05 \\
\hline CD-ROM & 05 \\
\hline Interface Usuário-Computador & 05 \\
\hline Publicações & 05 \\
\hline Bases de Dados & 04 \\
\hline Bibliotecários & 04 \\
\hline Ciência & 04 \\
\hline Sistemas de Informação Hospitalar & 04 \\
\hline
\end{tabular}

Fonte: Dados da pesquisa.

Analisando a TAB. 2, percebemos que os assuntos mais mencionados são: Bibliotecas Médicas, Brasil, Ciência da Informação, Bibliografia Nacional, Armazenamento e Recuperação da Informação, Serviços de Informação, Sistemas de Informação e Internet, com até 20 documentos relacionados. Sendo que 7 destes 8 assuntos pertencem à categoria Ciência da Informação, e 4 estão relacionados à Informática. 


\section{Autores}

Os 93 trabalhos indexados são de autoria de 172 pessoas ou instituições. Destes 172 autores, 7 (4\%) são institucionais e 165 (96\%) pessoais, sendo 115 (67\%) mulheres e 50 (29\%) homens (GRÁF. 1).

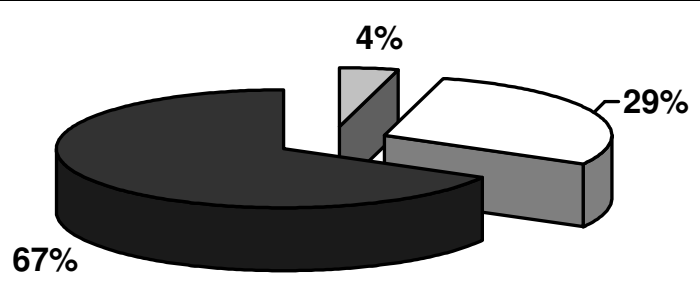

$\square$ Institucional $\square$ Masculino $\quad \square$ Feminino

GRÁFICO 1- Autores por tipo e gênero.

Fonte: Dados da pesquisa.

Dos 172 autores, apenas 123 não se repetem, ou seja, os 93 documentos encontrados são de autoria de 123 autores diferentes e 49 possuem autores que se repetem. Entre as repetições, estão de 2 a 5 trabalhos. Sendo que 90 (73\%) autores escreveram apenas um trabalho, $21(17 \%)$ realizaram 2 trabalhos, $7(6 \%)$ possuem 3, outros $4(3 \%)$ estão ligados a 4, e apenas 1 (1\%) autor escreveu 5 trabalhos (GRÁF. 2).

Assim, o autor indexado mais vezes na base não ultrapassa 5 documentos.

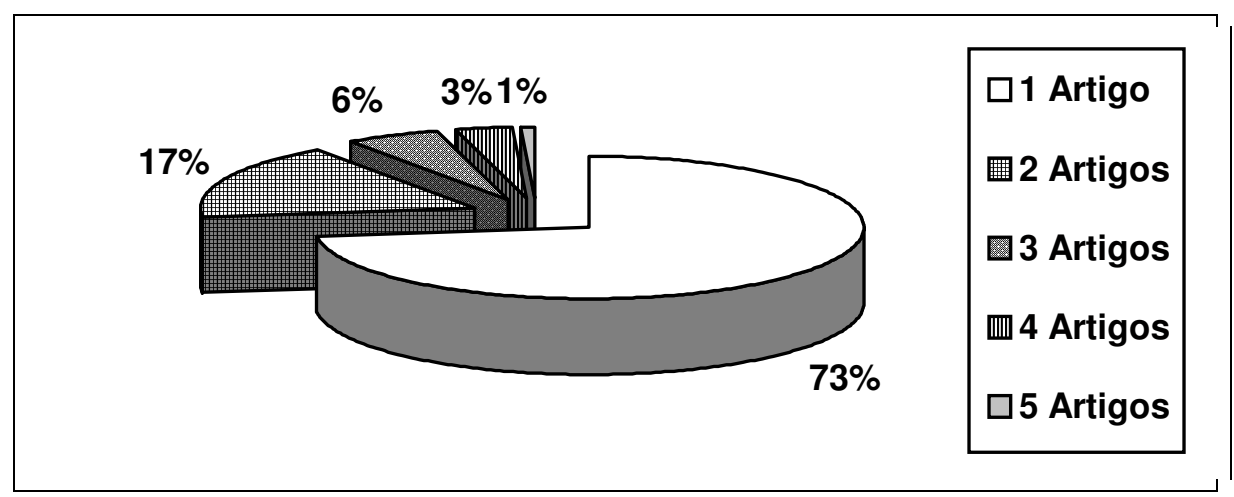

GRÁFICO 2 - Número de trabalhos por autor.

Fonte: Dados da pesquisa.

Dos 93 trabalhos, 58 (63\%) foram escritos apenas por um autor, 11 (12\%) por 2 autores, $14(15 \%)$ por 3, 5 trabalhos (5\%) por $4,4(4 \%)$ por 5 e $1(1 \%)$ trabalho por 8 autores (GRÁF. 3$)$. 


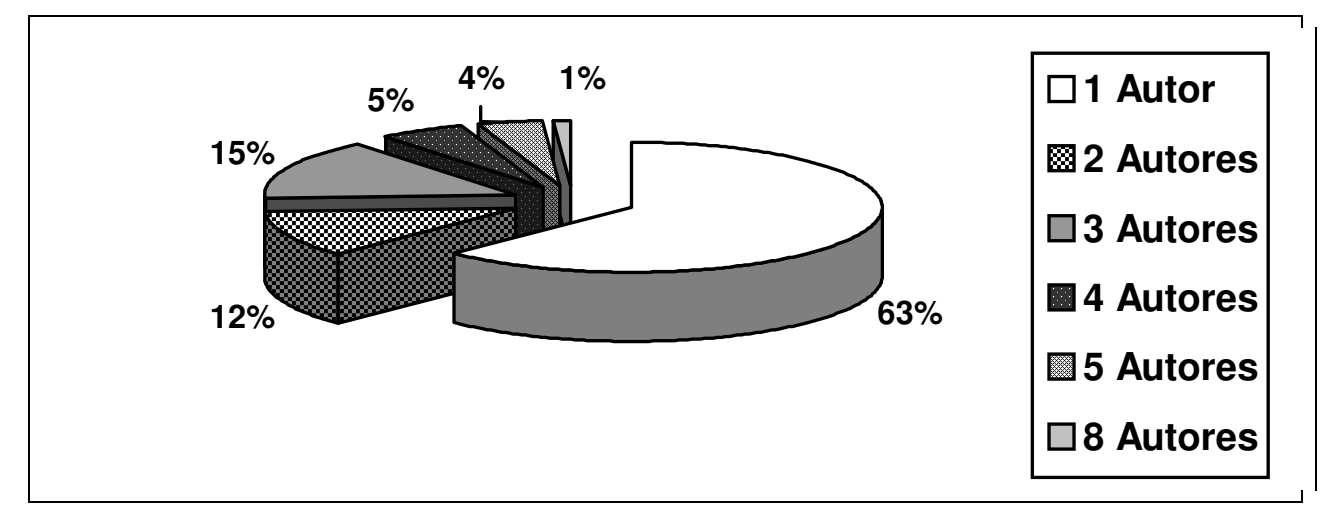

GRÁFICO 3 - Número de autores por trabalho.

Fonte: Dados da pesquisa.

\section{Local de publicação}

As cinco regiões brasileiras aparecem como local de publicação desses trabalhos, assim como os Estados Unidos e Cuba. No entanto, a maioria absoluta foi publicada na região sudeste do Brasil, com $87 \%$ dos trabalhos. As demais regiões brasileiras correspondem a $2 \%$, no caso do Centro-Oeste, $2 \%$ no Sul, e $1 \%$ cada para Norte e Nordeste. Estados Unidos e Cuba contribuíram com um trabalho cada.

Dos Estados brasileiros, temos São Paulo, Rio de Janeiro, Distrito Federal, Rio Grande do Sul, Mato Grosso do Sul, Bahia e Pará.

O GRÁF. 4 demonstra a divisão dos trabalhos por localidade.

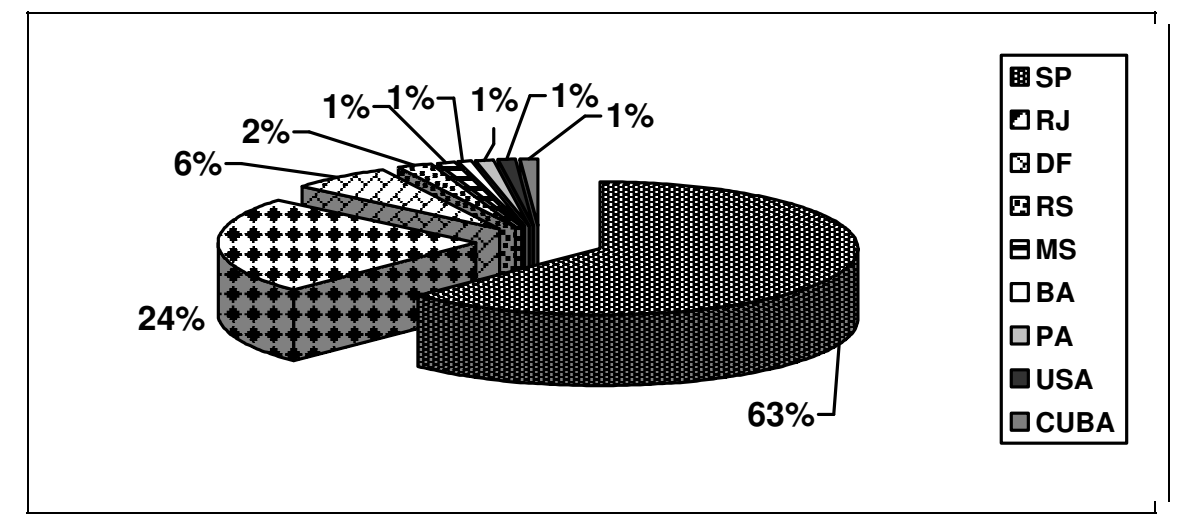

GRÁFICO 4 - Número de trabalhos por localidade.

Fonte: Dados da pesquisa.

\section{Data de publicação}

O período de publicação considerado neste artigo foi o de 1982 a 2006. Porém, identificamos publicações apenas a partir de 1983, e até os dias atuais. Além do ano de 1982, os anos de 1988, 1991 e 1993 não 
registraram trabalhos. Sendo que a última década foi responsável por $50.5 \%$ das publicações, conforme representado na TAB. 3.

TABELA 3 - Número de trabalhos por década

\begin{tabular}{c|c|c}
\hline PERÍODO & QUANTIDADE & $\mathbf{\%}$ \\
\hline \hline $1983-9$ & 17 & 18.3 \\
\hline $1990-9$ & 29 & 31.2 \\
\hline $2000-6$ & 03 & 50.5 \\
\hline TOTAL & $\mathbf{9 3}$ & $\mathbf{1 0 0}$ \\
\hline
\end{tabular}

Fonte: Dados da pesquisa.

O GRÁF. 5 representa a produção de cada período e o crescimento registrado nos últimos anos. Em média, foram publicados 4.4 trabalhos por ano. O ano com menor publicação foi o de 1984, com um trabalho apenas. Com 2 publicações cada, estão 1983, 1986, 1989, 1992 e 1994. Na década de 80, o ano que se destacou foi o de 1985, com 7 trabalhos. Já na década de 90, tem destaque o ano de 1995, com 6 trabalhos, e 2005 é apontado como o ano mais produtivo da atual década e de todas as outras, com 12 trabalhos e um crescimento de $36 \%$.

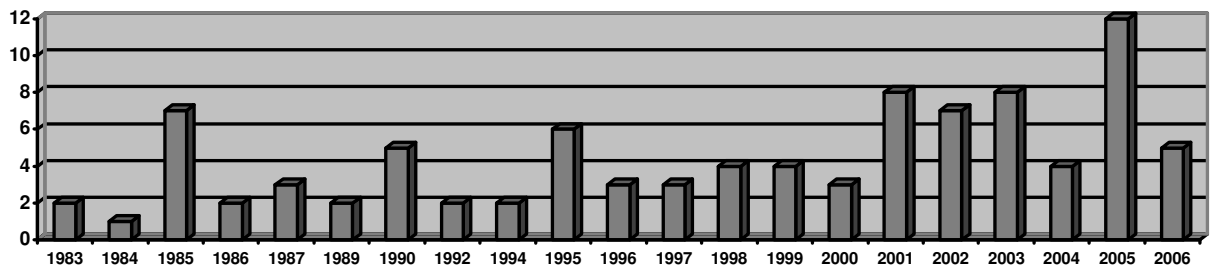

GRÁFICO 5 - Número de trabalhos por data de publicação.

Fonte: Dados da pesquisa.

\section{Tipo de publicação}

Os 93 trabalhos indexados na LILACS estão divididos em 5 tipos de publicação, sendo 48 (53\%) artigos de periódicos, 7 (8\%) livros, 2 (2\%) capítulos de livros, 5 (4\%) anais de eventos, 22 (32\%) monografias, sendo $16(17 \%)$ dissertações de mestrado, $14(15 \%)$ teses de doutorado e $1(1 \%)$ trabalho de conclusão de especialização (GRÁF. 6).

Destes trabalhos, $58 \%$ possuem resumo. 


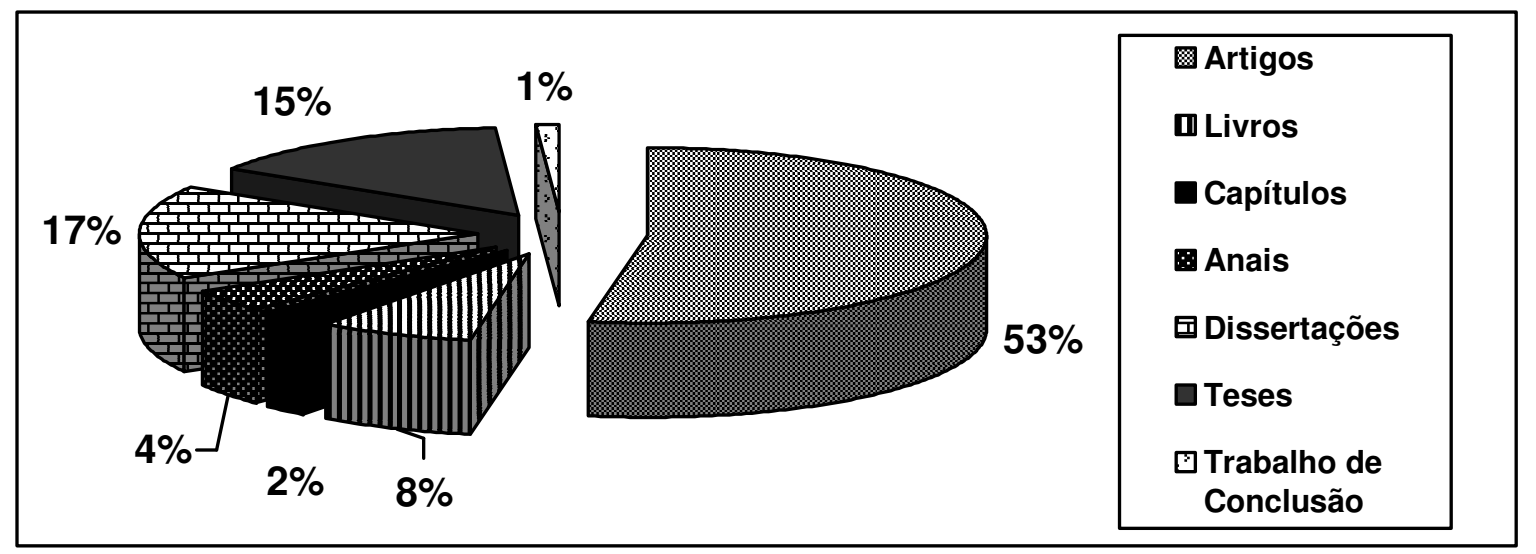

GRÁFICO 6 - Número de trabalhos por tipo de publicação.

Fonte: Dados da pesquisa.

Os 48 artigos foram publicados em 37 revistas diferentes. Todos os títulos são da área de saúde. Não há títulos de Ciência da Informação indexados na base LILACS.

Apenas um periódico publicou 4 artigos, 8 revistas publicaram 2 artigos e as demais editaram 1 artigo cada. O periódico que publicou mais artigos foi a Acta Cirúrgica Brasileira.

\section{Conclusão}

No momento em que esse levantamento foi realizado, a LILACS possuía 420.707 mil documentos. Destes, apenas 93 eram ou estavam atrelados ao campo Ciência da Informação em Saúde, ou seja, apenas $0.02 \%$.

Assim, concluímos tratar-se de um volume de publicação pouco expressivo, se comparado ao conteúdo total da base, e bastante pulverizado pela diversidade de documentos, autores e periódicos, concentrado no que se refere ao local de publicação e aos temas, que apresentaram pouca variação e se ativeram aos campos mais tradicionais da área.

A análise bibliométrica mostrou que a documentação mais vultosa na área em questão foi publicada na região sudeste $(86 \%)$, mais especificamente no Estado de São Paulo (63\%), e nesta década (50,5\%), por mulheres $(69,7 \%)$, sob a forma de artigo de periódico $(51,6 \%)$, em 37 revistas diferentes, destaque para a Acta Cirúrgica Brasileira, com 4 artigos.

A maioria dos documentos foi escrita apenas por um autor $(62,5 \%)$, sendo que a maioria dos autores escreveu apenas um trabalho $(73 \%)$, e os assuntos mais abordados foram: Bibliotecas Médicas, Brasil, Ciência da Informação, Bibliografia Nacional, Armazenamento e Recuperação da Informação, Serviços de Informação, Sistema de Informação e Internet. 
Apesar da presença de 62 descritores de assunto que contemplam diversos subcampos da Biblioteconomia, notamos a ausência de alguns termos amplamente utilizados na área, tais como: Catalogação Cooperativa, Arquitetura da Informação, Levantamento Bibliográfico, Comutação Bibliográfica, Consórcio de Bibliotecas, Biblioteca Eletrônica, Biblioteca Universitária e Competência ou Habilidade Informacional.

Embora tenhamos que considerar o fato de não haver títulos de Ciência da Informação indexados na LILACS e que o conhecimento gerado pelos profissionais da área pode ter sido publicado em revistas especializadas em Biblioteconomia, o levantamento mostrou que os bibliotecários da saúde não priorizam os periódicos especializados em saúde como veículo de divulgação de seu trabalho e de sua produção literária (ou talvez não sejam aceitos por eles), e que quando o fazem escrevem recorrentemente sobre os mesmos assuntos.

Dessa forma, sugerimos que um novo levantamento seja realizado focando as bases de dados da Biblioteconomia, para checarmos se realmente há pouca produção da Ciência da Informação em Saúde, se os profissionais da área não têm interesse em publicar, ou se priorizam outros periódicos e outras formas de comunicação, tais como Congressos e Simpósios.

\section{Referências}

ARRUDA, M. C. C.; MARTELETO, R. M.; SOUZA, D. B. Educação, trabalho e o delineamento de novos perfis profissionais: o bibliotecário em questão. Ciência da Informação, Brasília, v. 29, n. 3, p. 14-24, set./dez. 2000.

BARBOSA, R. R. Perspectivas profissionais e educacionais em biblioteconomia e ciência da informação. Ciência da Informação, Brasília, v. 27, n. 1, p. 53-60, jan./abr. 1998.

CAPURRO, R.; HJORLAND, B. O conceito de informação. Perspectivas em Ciências da Informação, Belo Horizonte, v. 12, n. 1, 2007. Disponível em: $<$ http://www.scielo.br/scielo.php?script=sci arttext\&pid=S1413-

99362007000100012\&lng=pt\&nrm=iso >. Acesso em: 20 jun. 2007.

CENTRO LATINO-AMERICANO E DO CARIBE EM CIÊNCIAS DA SAÚDE. Modelo da biblioteca virtual em saúde. Disponível em: $<$ http://bvsmodelo.bvsalud.org/php/level.php?lang=pt\&component=27\&it em=3>. Acesso em: 12 maio 2007.

LEITE, M. Biomédicas dominam pesquisa de impacto. Folha de São Paulo, 03 de dezembro de 2005. Disponível em: $<$ http://dalton.iq.ufrgs.br/lamoca/media/media folha.pdf $>$. Acesso em: 13 dez. 2005.

MARTINS, C. A.; KAVANAMI, R. M. M.; FANANI, A. Competências, habilidades e saberes necessários a um bibliotecário de Ciências da Saúde para recuperação de informações eletrônicas. In: CONGRESSO 
BRASILEIRO DE BIBLIOTECONOMIA, DOCUMENTAÇÃO E CIÊNCIA DA INFORMAÇÃO, 22., 2007, Brasília. Anais... Brasília: CBBD, 2007.

MIRANDA, A. C. C.; SOLINO, A. S. Educação continuada e mercado de trabalho: um estudo sobre os bibliotecários do Estado Rio Grande do Norte. Perspectivas em Ciência da Informação, Belo Horizonte, v. 11, n. 3, 2006.

$<$ http://www.scielo.br/scielo.php?script=sci arttext\&pid=S1413-

99362006000300007\&lng=pt\&nrm=iso >. Acesso em: 20 Jun. 2007.

OLIVEIRA, M. Origens e evolução da ciência da informação. In:

(Coord.). Ciência da Informação e Biblioteconomia: novos conteúdos e espaços de atuação. Belo Horizonte: UFMG, 2005. p.9-28.

PEREIRA, E. A. J. O perfil do bibliotecário da área de Ciências da Saúde em Santa Catarina. 2005. 121 f. Dissertação (Mestrado em Ciência da Informação) - Universidade Federal de São Catarina, Florianópolis, 2005.

SARACEVIC, T. Ciência da informação: origem, evolução e relações. Perspectivas em Ciência da Informação, Belo Horizonte, v. 1, n. 1, p. 4162, jan./jun. 1996.

TARAPANOFF, K.; SUAIDEN, E.; OLIVEIRA, C. L. Funções sociais e oportunidades para profissionais da informação. DataGramaZero, Revista de Ciência da Informação, Campinas, v. 3, n. 5, out. 2002. Disponível em: <http://www.datagramazero.org.br/out02/Art 04.htm>. Acesso em: 10 dez. 2004. 